Краснов Алексей Юрьевич

аспирант кафедры современной социологии социологического факультета

Московского государственного университета

имени М.В. Ломоносова

\section{ПОДХОДЫ К ИЗУЧЕНИЮ ПРОФЕССИОНАЛИЗМА В КОНЦЕПЦИЯХ ЗАПАДНЫХ СОЦИОЛОГОВ}

Аннотация:

В настоящей статье рассматриваются различные точки зрения на трактовку профессионализма как социального явления в западной социологии профессии. Осуществляется сравнительный анализ понятий «профессия» $и$ «профессионализм» 6 западной и отечественной традиции. С опорой на классические социологические теории приводятся четыре основных концептуальных подхода в теории профессионализма: функционалистский, критический, атрибутивный и герменевтический, в рамках каждого из которых автор обращает внимание на отдельные аспекты сущности профессионализма. В работе раскрываются ключевые особенности и принципиальные различия данных подходов, которые могут рассматриваться комплексно. В соответствии с атрибутивным подходом автор перечисляет характерные черты профессий в понимании западных специалистов. В заключение отмечены современные факторы и формируемые тенденции, влияющие на профессионализацию.

Ключевые слова:

современное общество, профессиональная структура, профессионализм, профессиональная группа, профессиональная стратификация, престиж профессий, социология профессии, трудовая сфера.
Krasnov Aleksey Yuryevich

PhD student Modern Sociology Subdepartment, Sociology Department,

Lomonosov Moscow State University

\section{APPROACHES TO STUDYING PROFESSIONALISM IN THE CONCEPTS OF WESTERN SOCIOLOGISTS}

Summary:

The paper discusses different points of view on the interpretation of professionalism as a social phenomenon in Western sociology of the profession. The concepts of profession and professionalism are compared in Western and Russian tradition. Based on classical sociological theories, the research describes four basic conceptual approaches to dealing with the theory of professionalism: functionalist, critical, attributive, and hermeneutic ones. The author highlights the aspects of professionalism in the context of each of them. The study reveals the key features of and fundamental differences in these approaches that can be comprehensively considered. Within the framework of the attributive approach, the author presents the characteristics of professions from the perspective of Western experts. In conclusion, the research identifies modern factors and emerging trends affecting the professionalization.

Keywords: modern society, professional structure, professionalism, professional group, professional stratification, occupational prestige, sociology of the profession, labor field.

В теории социологии профессии профессионализм как социальное явление может рассматриваться на основе логики различных подходов. Прежде всего следует отметить, что отличительная особенность данной отрасли социологии состоит в том, что акцент в ней сделан на изучении профессиональных групп как отдельных сообществ или корпораций, целенаправленно объединяющих людей в общую систему разделения труда.

Известно, что изначально термин «профессия» (profession) происходит от латинского profiteor - «объявляю своим делом» [1]. В англоязычных социологических словарях и справочникаx profession oпределяется как занятие (occupation) по большей части представителей среднего и высшего среднего класса, характеризуемое высоким уровнем технической и интеллектуальной компетентности [2] (например, врач, юрист, инженер - профессии, требующие сложного обучения и высокой квалификации). Таким образом, в западном социологическом понимании профессия (profession) является более сложным и высокостатусным родом деятельности индивида, приносящим ему средства к существованию и общественный престиж, нежели просто рядовые занятия (occupation), не требующие длительного обучения, фрильтрационных экзаменов и серьезной практической подготовки (в частности, таксист, официант, секретарь, делопроизводитель, менеджер продаж, охранник, уборщик, грузчик, курьер и пр.).

В свою очередь в русском языке термин «профессия», как правило, используется в самом широком смысле слова и скорее тождествен категории «занятие человека в жизни», которая позволяет удовлетворять какие-либо социальные потребности и приносит ему доход (повар, учитель, строитель, судья, переводчик и др.).

Являясь по сути родом трудовой деятельности в системе общественного разделения труда, профессия обычно выступает важнейшей составляющей социального статуса и становится основным источником существования человека, требуя от него владения теоретическими знаниями и 
практическими навыками. Последние приобретаются в результате специальной подготовки и получения длительного фрормального образования в образовательном учреждении, имеющем соответствующий статус и разрешение на подготовку профессионалов разных уровней.

В отечественной практике, кроме того, обычно используется градация на рабочие и интеллектуальные профессии. От основного понятия «профессия» их отличают такие термины, как «специальность», «специализация» и «квалификация», которые соотносятся как общее и частное.

В западной социологической теории профессии на сегодняшний день сложилось несколько взглядов на понимание профессии и профессионализма. Как социальное явление они могут рассматриваться с помощью четырех различных теоретических подходов: функционалистского, критического, атрибутивного и герменевтического.

Функционалистский, или позитивистский, подход к профессии тесно связан с теорией социального неравенства и подразумевает в качестве ключевой характеристики выделение функции профессии при разделении труда в обществе, ставя главным вопросом то, какие социальные потребности удовлетворяются функциями конкретных профессий [3]. Основными представителями данной концепции являются Г. Спенсер, Э. Дюркгейм, Т. Парсонс, К. Девис, У. Мур.

Еще основоположник теории функционализма Г. Спенсер рассматривал общества как живые организмы, составленные из многих частей: военной, экономической, медицинской, религиозной. Каждая часть социума в таком организме выполняет отдельную функцию. Чем больше различия между последними, тем труднее одной части заменить другую [4].

Э. Дюркгейм, развивший теорию Г. Спенсера, представлял профессионализацию как позитивный и прогрессивный процесс, который обеспечивает «общее здоровье социального тела» и способствует осуществлению социальных преобразований таким образом, чтобы конфликт и дезинтеграция в обществе оставались минимальными [5].

В середине XX в. К. Девис и У. Мур на основе концепции Э. Дюркгейма представили классическую функционалистскую теорию социального неравенства. Согласно ей профессиональное неравенство помогает обществу обеспечивать такие условия, при которых самые важные и сложные виды деятельности выполняют наиболее умелые его члены [6].

Позднее Т. Парсонс определял профессии как структурный элемент современного общества, направленный на общее повышение социальной адаптивности, а профессионал в его понимании - это идеальный гражданин идеальной страны, нацеленный на достижение успеха. Согласно исследователю, «профессиональный тип очерчивает такую институциональную рамку труда, в которую внесены многие важные социальные функции, особенно занятия наукой, профессиональной подготовкой и практическим применением в медицине, технологии, праве, преподавании. При этом критерии профессионализма - требование формальной "технической подготовки", сопровождающейся институциализированными моделями контроля над адекватностью образования и в отношении компетенции обученных индивидов; преобладание интеллектуального компонента, который создает ценностный вектор для профессионала, действующего в рамках инструментальной рациональности» [7, с. 57].

Критический подход базируется на социологической теории конфликта К. Маркса и включает марксистское и неомарксистское понимание профессии. Он снижает значение предыдущего подхода, противореча ему в том, что профессионалы всегда действуют во имя общественного блага, не считая возможным ограничиваться фриксированным набором атрибутов профессиональной деятельности. В соответствии с данной концепцией каждая профессия стремится поддерживать определенный статус-кво, удерживать или захватывать власть, ресурс и наиболее выгодное положение в стратификационной системе [8].

Поэтому профессионализация оказывается непрерывным процессом создания и контроля рынка определенных услуг, предоставляемых конкретной профессией, а в конечном счете - стремлением к достижению высокого статуса и восходящей социальной мобильности самих профессионалов. Этот подход в западной социологии также называется профессиональным контролем (the occupational control approach) и имеет корни в теориях конфликта и действия, рассматривающих общество как борьбу различных групп за соблюдение собственных интересов [9]. В таком понимании каждая профессия стремится ясно очертить круг вопросов, относящихся к сфере ее компетентности, ограничивая профессиональный взгляд на мир и монополизируя профессиональное знание как собственность. Требование правового закрепления уникальной компетентности - базовая стратегия профессионализма, а существенной частью этого процесса выступает контроль профессионального отбора. В результате этого достижения профессионального статуса должны обеспечивать высокие материальные награды и - самое главное - исключать внешние оценки качества услуг, гарантируя тем, кто допущен к непосредственной практике, безопасность как владельцам этого капитала. Отсюда происходят серьезные конфликты между профессионалами и теми, кто посягает на их монополию статуса, экспертизы и престижа. 
Атрибутивный подход, имеющий также название «теория черт», обращается к выделению характеристик и атрибутов, отвечающих идеальному типу профессии, а также сосредоточивает свое внимание на вопросах профессиональной компетентности. Представителями данной концепции являются А. Флекснер, Е. Гринвуд [10], Л.К. Ризер, И. Эпштейн [11], Дж.Л. Миллерсон [12]. Согласно этой теории конкретные профессии рассматриваются через присущие им атрибуты или черты, когда ставится вопрос о том, является ли истинной профессией обсуждаемый вид занятий или нет, а также каковы общие характеристики, отличающие профессии от не-профессий.

В 1915 г. А. Флекснер одним из первых выделил список атрибутов, которые, как предполагалось, отвечают идеальному типу профессионала. С этого момента последующие представители данного подхода создавали новые перечни этих атрибутов и не могли достичь полной согласованности в попытках отличить профессии от не-профрессий.

В рамках концепции предпринимались многочисленные попытки сфрормулировать атрибуты профессионализма, которые затем позволили бы оценить, насколько тот или иной вид занятий приближен к идеальному типу профессии. В данном случае профессионализация могла быть осмыслена как процесс, за счет которого определенный вид деятельности может претендовать на статус профессии, а следовательно, на награды и привилегии, соответствующие этому статусу.

В изучаемой теории один и тот же вид занятий разные авторы определяли как «профессию», «полупрофессию» или «не-профеессию» в зависимости от того, какой список признаков выбирается в качестве стандарта. Например, среди наиболее важных атрибутов классической профессии А. Флекснер рассматривал следующие: 1) вовлеченность человека в интеллектуальную деятельность, предполагающую индивидуальную ответственность; 2) привлечение науки и обучение в практических целях; 3) применение знаний посредством технологий, передаваемых через образование; 4) самоорганизация; 5) альтруистическая мотивация; 6) наличие профеессионального самосознания.

Позднее Дж.Л. Миллерсон предлагал сходный набор признаков професссионализма: 1) применение человеком навыков, основанных на теоретических знаниях; 2) образование и подготовка по этим навыкам; 3) компетентность профессионалов, удостоверенная экзаменами; 4) правила поведения, которые формируют профессиональную общность и утверждаются профессиональным сообществом; 5) оказание услуг ради общественного блага; 6) профессиональная ассоциация, которая организует своих членов.

Особенным является четвертый - герменевтический - подход, который сосредоточивает внимание на социокультурных смыслах профессии, воплощаемых в повседневных практиках специалистов, направленных на достижение понимания непосредственного повседневного опыта профессионалов. Герменевтическая теория сложилась благодаря исследованиям И. Гофрмана. Он обращается к стихийно развивающемуся человеческому опыту, который формируется в виде повседневного знания [13]. Открытие такого знания продемонстрировало огромное пространство неопределенностей, в том числе в профессиях и организациях, складывающихся автономно от административных регламентаций [14].

Герменевтика в этой области социологии позволяет интерпретировать осмысленные действия профессионалов как тексты. На основе данного метода строится френоменологический подход к исследованию профессии, который позволяет изучать ее как относительно замкнутый и самодостаточный жизненный мир, интерпретировать взгляды профессионалов на их повседневность. Феноменологическая социология профессий, таким образом, подробно описывает содержание и структуру сознания субъектов, определяет качественные различия в их переживаниях и выявляет их сущностный смысл, пытается проникнуть за пределы непосредственно переживаемого смысла, чтобы сделать незримое зримым [15].

Среди наиболее известных западных исследователей в области социологии профессии следует прежде всего обратить внимание на теоретические изыскания Дж. Оллсоп, К. Джонс, Э. Кулманн, М. Сакса, Э. Эбботта [16, с. 3]. В частности, работы социологов Дж. Оллсоп, К. Джонс, Э. Кулманн затрагивают многочисленные теоретические аспекты социального взаимодействия между профессионалами, государством и потребителями в современной Европе на примере Германии и Великобритании.

Наиболее важный аспект выбора способа существования и воспроизводства профессионалов в современном обществе поднимается в работе Дж. Оллсоп и К. Джонс. По их заключению, признаком высокого статуса, автономности и привилегии профессии в западном обществе всегда считалась возможность саморегулирования. Именно эта значимая функция обеспечила то, что род занятий, обладающий ею, стал именоваться профессией. Саморегулирование позволяло отдельному роду деятельности устанавливать монополию на определенную область знания и, соответственно, превалировать на сложившемся рынке труда в частном или государственном секторе.

Одним из известнейших западных специалистов по социологии профессии является Э. Эбботт, который в целом оказал существенное влияние на британские и американские исследования 
в данной области, в частности в социологии медицины, теориях организаций, трудовых отношений и деловой этики. Кроме того, в одной из работ - «Система профеессий: эссе о разделении экспертного труда» - Э. Эбботт проанализировал социальные траектории более 50 профессий [17].

Наиболее ярким представителем неовеберианского направления в исследовании профрессиональных групп является М. Сакс, который ставит под сомнение универсальность неовеберианского подхода в социологии профессии, подчеркивая различную специфику его применения для англо-американской системы и системы континентальной Европы. Автор обращает внимание на особенности неовеберианской концепции на примере исследований альтернативных и вспомогательных профессий в сфере здравоохранения. В работе «Границы англо-американской социологии профессий: критика ортодоксальности современного неовеберианского подхода» он высказывает мнение, что социология профессий сосредоточена главным образом на изучении профессионализированных родов занятий, таких, например, как врачи и юристы [18], в то время как тема классификации профессиональных групп и вопросы о месте профессионализированных и непрофессионализированных видов деятельности остаются неразработанными. Ученый подчеркивает важность понимания различий между традиционными профессиями и альтернативными и вспомогательными.

Немецкий социолог Э. Кулманн рассматривает профессионализм как взаимодействие государства, профессионалов и потребителей их услуг. В работе «"Ответственные профрессионалы" и "разборчивые клиенты": изменения во взаимодействии медицинских профрессионалов, государства и общества» она на примере медицинской сферы показывает современные изменения во взаимоотношениях между профессионалами и потребителями [19]. По мнению данного автора, современные государства всеобщего благосостояния во многом зависят от профессионалов, так как работа государственного аппарата высоко оценивается только в том случае, если граждане видят, что в государстве деятельность профессионалов эффективна. Профессионалы являются своего рода посредниками между властью и гражданами. Все эти стороны непрерывно взаимодействуют и нуждаются друг в друге, при этом между ними неизбежны определенные пересечения интересов и конфллиты. Для осознания изменений и трудностей, с которыми сталкиваются современные сообщества, необходимо понимать роль и значение в них профессионалов и профессионализма.

Все рассмотренные подходы к профессии подчеркивают тот или иной аспект социальной идентичности традиционного профессионала и могут рассматриваться в комплексе. В целом профессионализм и профессионализацию, таким образом, можно охарактеризовать как процесс социального дистанцирования или обособления людей-экспертов от не-экспертов, определенное соревнование за ресурсы, власть и информацию между субъектами, выполняющими сходные виды занятий. Любая профессия в подобном понимании предполагает монополию, привилегированность и превосходство специализированного знания, полученного официальным и формальным образом, над обыденным опытом и навыками. Кроме того, профессионалы, защищая свой статус, всегда стремятся к самоорганизации и внутреннему контролю за сферой деятельности.

В контексте современности профессионализация, включающая уже названные образование, саморегулирование, контроль, ассоциацию и этику, находится в тесной взаимосвязи с развивающимися информационно-коммуникационными технологиями, расширяющейся глобальной экономикой общества потребления, новыми способами производства, трансформацией социальных институтов и процессов, а также с либерализацией многих областей жизни людей. Среди главных мегатрендов, влияющих на современную профессионализацию, можно отметить либеральные ценности глобализма, оптимизацию и рационализацию многих рутинных трудовых процессов, изменение рынка рабочей силы и капиталистической экономики в большинстве государств мира, модернизацию и автоматизацию промышленного производства, тотальную информатизацию всех сфер, миграцию и быструю урбанизацию, различия в условиях труда в разных странах, стандартизацию и унификацию норм права, реформирование системы образования, общую рационализацию труда и культуру ускоренной жизни социума.

Современность во многом изменила отношение индивида к выбору для себя одной-единственной профессии в качестве призвания на всю жизнь. Сегодня наметилась устойчивая тенденция менять в течение жизни несколько профессий и занятий, совмещать или чередовать их. Кроме того, важной дискуссионной проблемой становится вопрос - насколько можно считать профессионализмом и профессиями новые способы получения дохода, появившиеся в современном обществе, которые хотя и требуют определенных знаний, навыков и образования, но не связаны с непосредственным приобретением конкретной профессии в специализированном образовательном учреждении. К подобным новым занятиям-профессиям можно отнести торговлю товарами через интернет, финансовые спекуляции на различных электронных площадках, всевозможные виды обучения в Сети, продвижение товаров и услуг на сайтах и видеоканалах, рекламу 
в социальных сетях и видеоблогах, работу с криптовалютами и прочие технологичные занятия, в том числе те, которые сегодня выбирают многие так называемые самозанятые граждане.

\section{Ссылки:}

1. Большой энциклопедический словарь / под ред. А.М. Прохорова. 2-е изд., перераб. и доп. СПб., 2004.

2. Аберкромби Н., Хилл С., Тернер Б.С. Социологический словарь : пер. с англ. М., 2004. 620 с. ; Джери Д., Джери Дж. Большой толковый социологический словарь : пер. с англ. В 2 т. М., 1999.

3. Дюркгейм Э. О разделении общественного труда. М., 1996 ; Parsons T. The Social System. L., 1951.

4. Спенсер Г. Сочинения Герберта Спенсера. В 7 т. СПб., 1897-1900.

5. Durkheim E. Professional Ethics and Civic Morals. L. ; N. Y., 1957. 228 p.

6. Davis K., Moore W.E. Some Principles of Stratification // American Sociological Review. 1945. Vol. 10, no. 2. Annual Meeting Papers. P. 242-249.

7. Абрамов Р.Н. Профессиональный комплекс в социальной структуре общества (по Парсонсу) // Социологические исследования. 2005. № 1. С. 54-66.

8. Freidson E. Professional Dominance. Chicago, 1970 ; Larson M.S. The Rise of Professionalism. Berkeley, CA, 1977 ; Mills C.W. White Collar. N. Y., 1953.

9. Jones S., Joss R. Models of Professionalism // Learning and Teaching in Social Work / ed. by M. Yelloly, M. Henkel. L. ; Bristol, PA, 1995. P. 15-33.

10. Greenwood E. Attributes of a Profession // Social Welfare Institutions / ed. by M. Zald. L., 1965. P. 509-523.

11. Reeser L.C., Epstein I. Professionalism and Activism in Social Work: The Sixties, the Eighties, and Future. N. Y., 1990

12. Millerson G.L. The Qualifying Association. L., 1964.

13. Гофман И. Анализ фреймов: эссе об организации повседневного опыта. М., 2004.

14. Щепанская Т.Б. Антропология профессий // Журнал социологии и социальной антропологии. 2003. Т. VI, № 1. С. $139-161$.

15. Квале С. Исследовательское интервью / под ред. Д.А. Леонтьева. М., 2003.

16. Социальная динамика и трансформация профессиональных групп в современном обществе / под ред. В.А. Мансурова. M., 2007.

17. Abbott A. The System of Professions: an Essay on the Division of Expert Labor. Chicago, 1988.

18. Сакс М. Границы англо-американской социологии профессий: критика ортодоксальности современного неовеберианского подхода // Социальная динамика и трансформация профессиональных групп в современном обществе. М., 2007. C. 53-81.

19. Кульман Э. «Ответственные профессионалы» и «разборчивые клиенты»: изменения во взаимодействии медицинских профессионалов, государства и общества // Социальная динамика и трансформация профессиональных групп в современном обществе / под ред. В.А. Мансурова. М., 2007. С. 81-106.

\section{References:}

Abbott, A 1988, Essay on the Division of Expert Labor, Chicago.

Abercrombie, N, Hill, S \& Turner, BS 2004, Sociological Dictionary, Moscow, 620 p., (in Russian).

Abramov, RN 2005, 'Professional Complex in the Social Structure of Society (According to Parsons)', Sotsiologicheskiye issledovaniya, no. 1, pp. 54-66, (in Russian).

Davis, K \& Moore, WE 1945, 'Some Principles of Stratification', American Sociological Review, vol. 10, no. 2, Annual Meeting Papers, pp. 242-249.

Durkheim, E 1957, Professional Ethics and Civic Morals, London, New York, 228 p.

Durkheim, E 1996, On the Division of Social Labor, Moscow, (in Russian).

Freidson, E 1970, Professional Dominance, Chicago.

Greenwood, E 1965, 'Attributes of a Profession', in M Zald (ed.), Social Welfare Institutions, London, pp. 509-523.

Hoffman, I 2004, Analysis of Frames: an Essay on the Organization of Everyday Experience, Moscow, (in Russian).

Jerry, D \& Jerry, J 1999, Big Dictionary of Sociological Dictionary, in 2 vols, Moscow, (in Russian).

Jones, S \& Joss, R 1995, 'Models of Professionalism', in M Yelloly, M Henkel (ed.), Learning and Teaching in Social Work, London, Bristol, PA, pp. 15-33.

Kulman, E 2007, '"Responsible Professionals" and "Discriminating Clients": Changes in the Interaction of Medical Professionals, State and Society', in VA Mansurov (ed.), Social Dynamics and Transformation of Professional Groups in Modern Society, Moscow, pp. 81-106, (in Russian).

Kvale, S 2003, Research Interview, Moscow, (in Russian).

Larson, MS 1977, The Rise of Professionalism, Berkeley, CA.

Mansurov, VA (ed.) 2007, Social Dynamics and Transformation of Professional Groups in Modern Society, Moscow, (in Russian). Millerson, GL 1964, The Qualifying Association, London.

Mills, CW 1953, White Collar, New York.

Parsons, T 1951, The Social System, London.

Prokhorov, AM (ed.) 2004, Great Encyclopedic Dictionary, $2^{\text {nd }}$ ed. St. Petersburg, (in Russian).

Reeser, LC \& Epstein, I 1990, Professionalism and the Socialism in Social Work: The Sixties, the Eighties, and Future, New York.

Sachs, M 2007, 'Borders of the Anglo-American Sociology of Professions: A Critique of the Orthodoxy of the Modern NeoWeberian Approach', Social Dynamics and Transformation of Professional Groups in Modern Society, Moscow, pp. 53-81, (in Russian).

Schepanskaya, TB 2003, 'Anthropology of Professions', Zhurnal sotsiologii i sotsial'noy antropologii, vol. VI, no. 1, pp. 139161, (in Russian).

Spencer, G 1897-1900, Works of Herbert Spencer, in 7 vols, St. Petersburg, (in Russian). 